\title{
Latent Dimensions of Executive Functions in Early Childhood
}

\author{
Scott L. Decker ${ }^{1}$ - Greer Alexander Ezrine ${ }^{2}$ - Joseph Ferraracci ${ }^{1}$
}

Received: 18 November 2015 /Revised: 29 March 2016 / Accepted: 31 March 2016 / Published online: 8 April 2016

(C) American Academy of Pediatric Neuropsychology 2016

\begin{abstract}
Executive functions (EF) are known to be a multidimensional construct in adults; however, the underlying dimensions of EF in early childhood are unclear. Theoretical models of EF have generally suggested the importance of language, attention, and inhibition abilities as developmental foundations for EF abilities. This study investigated the construct validity of EF by administering a diverse battery of measures of EF along with cognitive measures representing different theoretical models of EF (language, attention, and inhibition) to 70 preschool children. The EF battery included measures of working memory (verbal and nonverbal), set shifting, and problem solving. A maximum likelihood factor analysis with oblimin rotation resulted in a three factor model; however, only two factors (language and inhibition) were related to EF measures. Results from the current study suggest language and behavioral inhibition are two foundational latent abilities for the development of EF abilities in early childhood. Attention, although important in many EF theories, may also be important for cognitive development but appears to be less important for EF abilities in preschool children. Results from this study suggest executive functions in early childhood consist of multiple distinct but interrelated components that are associated with underlying cognitive foundations.
\end{abstract}

Scott L. Decker

sdecker@mailbox.sc.edu

1 University of South Carolina, 1512 Pendleton Street, Columbia, SC 29208, USA

2 Georgia State University, Atlanta, GA 30302, USA
Keywords Executive function · Factor analysis · Development $\cdot$ Cognitive

\section{Introduction}

Executive functions (EF) involve a host of cognitive operations that typically included aspects of self-regulation of goal directed behavior involving complex problem-solving (Barkley 1997a, b, 2001; Lezak 1995; Miller 2005; Pennington 2009). Impairments in EF were first noted in adults with injuries to the frontal lobes of the brain (Halstead 1947; Luria 1973, 1980). Indeed, developmental changes in EF are linked to developmental changes in the frontal cortex of the brain which occur across childhood and adolescence (Golden 1981; Diamond 2001, 2002). EF abilities grow rapidly in early childhood between the ages of 4 and 6 and are associated with numerous developmental, academic, and clinical outcomes (Espy et al. 1999; Sowell et al. 2002). EF deficits, from injury or atypical development, are associated with adverse developmental outcomes that include attention deficit hyperactivity disorder (ADHD) and autistic spectrum disorders (ASD; Pennington and Ozonoff 1996), traumatic brain injury (Beauchamp et al. 2011), emotional and social competence (Kochanska et al. 1996), behavioral control (Eisenberg et al. 1997), social cognition (Perner and Lang 1999), school adjustment (Blair 2002; Bodrova and Leong 2006), and academic achievement (Bull and Scerif 2001; Duncan et al. 2007; McClelland et al. 2007).

Given the importance of EF, understanding its development has been an active area of research (Carlson 2005). Identification of the underlying cognitive constructs that may serve as a developmental foundation for EF would not only inform theoretical models of EF but would also have applied value in identification and intervention for many 
developmental disabilities (Garon et al. 2008). Toward this goal, research has focused on understanding the underlying dimensions of EF in early childhood (Lehto et al. 2003; Miyake et al. 2000; Van der Ven et al. 2013) and how EF dimensions change across development (Espy 1997; Levin et al. 1991; Smidts et al. 2004; Welsh et al. 1991). However, there is a lack of consensus on the underlying constructs of EF in early childhood (Anderson et al. 2008).

Several studies have supported a single factor model of EF in early childhood that is primarily characterized by attention (Klenberg et al. 2001; Lerner and Lonigan 2014). For example, a central attention system or a "central executive system" has been prosed as a core component in some models of EF (Baddeley 1986; Posner et al. 2012). The general role of attention in these theories is to filter and prioritize information processing. Factor analytic studies have found attention to be a distinct factor among EF measures and to have a different developmental course then other EF abilities (Klenberg et al. 2001). There is also evidence for differentiated components within a specific attention factor (Breckenridge et al. 2013). Supporting the role of attention are studies demonstrating improvements in sustained attention between the ages of 3 and 5 that correspond to changes in EF (Corkum et al. 1995; Mahone et al. 2001).

Similarly, Barkley (1997a, b, 2001) has proposed a model of EF with multiple components that are unified by inhibition. According to Barkley, deficits in motor inhibition result in a cascade of deficits in EF that include working memory (WM) and complex problem solving. Most models of EF in preschool children include a specific dimension of inhibition that has been supported by factor analytic research. However, some studies have found inhibition and "set-shifting" components of EF are indistinguishable (Van der Ven et al. 2012). As such, inhibition appears to be important for EF but it is unclear if it is important for all EF skills or only a subset of EF skills.

Several other models have emphasized the role of language and language development in EF. Indeed, several classic and contemporary theorists have postulated that language is a core ability that serves as a foundation for complex mental activity involved in higher-level complex thinking (Baddeley et al. 1998; Barkley 1997a, b; Luria 1961; Vygotsky 1986; Zelazo 2004). In particular, self-directed speech has been asserted as playing a transformative role in the development of EF in early childhood, facilitating the move from external regulation to internal or self-regulation. Internalized, self-directed speech may serve to enhance the process of self-regulation, providing a form of self-guidance and direction by facilitating problem solving (Vygotsky 1978). Indeed, children with language delays or specific language impairments have deficits on EF measures (Vugs et al. 2014). The role of pragmatic language (i.e., social communication) has been identified as an important foundation for EF development in children (Blain-Briere et al. 2014). Unfortunately, pure language and pragmatic language tasks are under-represented in many EF models because they are frequently used as a covariate, since many theoretical models depict language as separate from EF (Müller et al. 2009).

Factor and confirmatory factor analytic techniques have been the primary methodology used to identify latent dimensions of EF (Lehto et al. 2003; Miyake et al. 2000; Stuss and Alexander 2000). Some studies, using young adults, have found a single underlying latent higher-order dimension (Decker et al. 2007); however, several other studies have identified inhibition, attention flexibility (set-shifting), and working memory as related, yet separable, dimensions of executive functioning in both children and adults (Lehto et al. 2003; Miyake et al. 2000). Moreover, factor analytic studies of children and adolescents have identified problem solving, planning, and speeded responding (fluency) as specific aspects of EF (Levin et al. 1991; Welsh et al. 1991).

Of the few studies which directly investigated EF in preschool children, the results are unclear. One key study investigated various models with different specifications of EF components found a single unitary factor provided the best fit to the data (Wiebe et al. 2008). A follow-up study in a sample of 3-year-old children confirmed a single factor of EF provided the best fit for preschool children (Wiebe et al. 2011) In contrast, a two-factor model consisting of inhibition and working memory flexibility was found in one study that was invariant across sex (Monette et al. 2015). Similarly, another study investigated numerous EF models and found a two-factor model consisting of WM and inhibition provided the best fit (Miller et al. 2012).

A ubiquitous problem across all published studies is the overlapping task demands of EF measures. Wiebe et al. $(2008 ; 2011)$ referred to this issue as task impurity. Furthermore, Miller et al. (2012) suggested single factor models arise primarily due to ".... an overlap in working memory and inhibition task demands." (p. 416). Because most EF measures involve overlapping task demands, the current study included three more "pure" measures of the underlying constructs purported to underlie EF by different theories: language, inhibition, and attention. Consequently, including relatively "pure" measures, for EF and non-EF, constructs may help clarify underlying latent dimensions when using factor analysis.

\section{Rationale for Current Study}

The current study examined the underlying dimensions of EF constructs in a preschool sample using a battery of EF measures. Similar to previous studies, measures of EF included various measures of working memory (verbal and nonverbal), set shifting, and problem-solving. However, unlike previous studies, specific cognitive measures were included based on their theoretical importance for EF in preschool children. 
These measures were intended to provide more "pure" measures of underlying cognitive constructs that may serve as a developmental foundation for EF. As identified in the review of research, measures of language ability (receptive and pragmatic), attention, and behavioral inhibition were administered in conjunction with EF measures. As an a priori hypothesis, we propose language, inhibition, and attention will form the basis of three factors that serve as the foundation for executive functions. Executive function measures most reliant upon cognitive demands represented by each of these measures are expected to load on the same factor. Other possible empirical outcomes are obviously possible and informative. Cognitive measures may load on a single factor in conjunction with a separate EF factor. Furthermore, it may be the case all EF measures load on similar factors with developmental measures of cognition loading on a separate factor. However, the expectation for whatever EF dimensions are extracted, the dimension will be associated with a single developmental cognitive ability (language, inhibition, and attention).

\section{Method}

The current study examined the latent structure of EF abilities in preschool children. The factor analytic procedure with maximum likelihood extraction and direct oblimin rotation was selected to address several problems reported in previous research studies. First, given the number and nature of EF dimensions in preschool children is considered unresolved (Barkley 1997a, b, 2001; Rosenberg 2014), there is a need for an exploratory approach, which justifies the use of factor analysis. However, since the current study was informed by a theoretical background, the use of maximum likelihood approach with model fit criteria (chi-square) provides an evaluation of model-fit. The integration of both EFA and CFA provided a more integrated view in which to evaluate the results of the study.

\section{Participants}

The sample was composed of 70 preschool children who, upon entry into the study, ranged in age from 3 years 0 months to 5 years 8 months $\left(M_{\mathrm{age}}=3\right.$ years 9 months, $\mathrm{SD}_{\text {age }}=5.14$ months). Children were recruited via informed parental consent from two child development centers associated with Georgia State University. The sample was fairly evenly split between girls (41\%) and boys (59\%) in the sample. The racial make-up of the sample was $44 \%$ Caucasian, $41 \%$ African American, $3 \%$ Asian, and $12 \%$ Biracial/Other. Breakdown of the sample by marital status of the participants' parents was $79 \%$ married and $21 \%$ unmarried. Mean parent maternal education level of the sample was
18.3 years ( $\mathrm{SD}=2.45$ years). Mean parent paternal education level was 16.9 years ( $\mathrm{SD}=2.94$ years). All of the children in the sample were English speaking. English was the primary language spoken in the home of $95 \%$ of the sample, while $5 \%$ of the sample was bilingual. Other languages reportedly spoken in the home included German, Chinese, and Malay. Parental report of handedness was $64 \%$ right-handed, $15 \%$ left-handed, $10 \%$ ambidextrous or not sure, and $10 \%$ not reported. All children were typically developing; that is, no child included in the study had any known developmental delay or neurological disorder evidenced by parental report. Missing data was handled via two methods. Participants with greater than $10 \%$ of missing data were excluded from the analysis. Mean substitution was used for other missing data points. This criterion resulted in one participant being excluded from the analysis. Incomplete data for other cases was resolved using a mean substitution procedure that was used for less than $8 \%$ of the data points.

\section{Measures}

As previously mentioned, the study involved both a battery of EF measures as well as developmental measures of language, inhibition, and attention to help clarify the demands of various EF measures. Each of these measures will be reviewed in detail. All measures used in this study were administered in accordance with the standardized published instructions as outlined in the administration manual of each test.

\section{Executive Function Measures}

The battery of EF measures used in this study was based upon their established use in clinical and/or research settings, developmental appropriateness, and availability. At the present time, very few normreferenced standardized measures of EF are available for use with preschool-aged children.

Working Memory Verbal and Nonverbal memory measures were used from the Stanford Binet Intelligence Scales, Fifth Edition (SB-5; Roid 2003). The SB-5 is a standardized, normreferenced measure appropriate for use with very young children. Normative data for the SB-5 were gathered from 4,800 individuals between the ages of 2 and $85+$ years. The normative sample matches the 2000 US Census, stratified by gender, race/ethnicity, geographic region, and socioeconomic status. Reliabilities for SB-5 scores range from 0.84 to 0.89 across all age groups. A number of studies provide evidence for concurrent and criterion validity (see Roid 2003 for details). For this study, the SB-5 Memory for Sentences, Last Word subtest was chosen to measure verbal working memory and the Block Span subtest was chosen to measure nonverbal working memory. They are described here: 
1. Verbal Working Memory (VWM). The Memory for Sentences, Last Word subtest is a measure of short-term and working memory for verbal information. The examiner reads a sentence and asks the child to repeat the sentence verbatim. On more difficult items, the examiner reads brief questions and the child must respond with the last word in each question.

2. Nonverbal Working Memory (NWM). The Block Span subtest is a measure of short-term and working memory for visual-spatial information. The examiner taps blocks in a sequence. The child is asked to recall the sequence of block taps and to respond by sorting the sequence into those taps occurring in the yellow row versus those occurring in the red row.

Problem-Solving: Tower (TOW) The Tower measure from the NEPSY (Korkman et al. 1998), which is a standardized and norm-referenced instrument designed to assess neuropsychological development in preschool and school-aged children. The NEPSY standardization sample was comprised of 1,000 children ranging in age from 3 to 12 years. The sample was stratified to match 1995 US Census data based on age, gender, race/ethnicity, geographic region, and parent education. Reliability studies indicate moderate to high internal consistency or stability of NEPSY subtest scores, ranging from 0.50 to 0.91 . Tower was selected to measure problem solving and planning ability, which is an important component of EF. The child is asked to move three colored balls to a target position on three pegs in a prescribed number of moves. There are also rules to which the child must adhere on this timed task (e.g., only one ball can be moved at a time; balls must remain on the pegs when they are not being moved).

\section{Set-Shifting: The Dimensional Change Card Sorting Task} (DCCS; Frye et al. 1995) is based on Kirkham et al. (2003) version of Frye et al. (1995) DCCS task. The task measures the child's ability to switch categorical sorting dimensions (e.g., color, shape) based upon specified rules. After initial training, the child is asked to sort cards by a series of rules, which are changed after every six cards. The child must keep the current rule set in mind, sort by that rule, then switch sets a total of four times (i.e., sort by color, then shape without interfering color, then shape with interfering color, finally color).

Set-Shifting/Inhibition: Cat-Dog The Cat-Dog task, based on the Day-Night task (Gerstadt et al. 1994) was chosen due to its wide use in developmental studies of EF. It is a strooplike inhibition task is based on Gerstadt et al. (1994) DayNight task. This experimental task measures the child's ability to act according to remembered instructions and to inhibit a prepotent response. The examiner trains the child to say "cat" whenever a picture of a dog is shown and to say "dog" whenever a picture of a cat is shown. After the initial training, the child's responses are recorded on a series of 16 stimulus cards.

\section{Developmental Cognitive Measures}

The following measures were included to provide cognitive markers of different theories to help clarify the underlying EF constructs. As reviewed in the introduction, language, attention, and inhibition have been identified by different theories as important for the developmental foundation of EF in children. Consequently, as tested by this study, these cognitive markers should load on dimensions of EF in which they have the greatest influence. Two individually administered, normreferenced measures of language ability were selected to assess each child's initial receptive and expressive language skills. The measures were chosen due to their wide use in school, clinical, and research settings. Additionally, theoretical models of EF involving language are unclear as to whether basic language (e.g., vocabulary) or social language (pragmatic language) are the developmental basis for EF in children. Both measures used in this study were appropriate for use with preschool children and required no reading or writing.

Language The Peabody Picture Vocabulary Test, Third Edition (PPVT-III: Dunn and Dunn 1997) was used to measure initial receptive vocabulary. Children are asked to select the picture (out of an array of four pictures) that best describes the meaning of the stimulus word. The PPVT-III has excellent psychometrics with a normative sample including 2,725 persons and median reliability (Cronbach's alpha) ranging from 0.92 to 0.98 . The split-half reliabilities for the 25 age groups ranged from 0.86 to 0.97 , with a median of 0.94 for both forms. The alternate forms reliabilities range from 0.86 to 0.96 with a median correlation of 0.94 . Concurrent validity correlations of the PPVT-III with scores of the Wechsler Intelligence Scale for Children, Third Edition (WISC-III) range from 0.82 to 0.92 for the verbal, performance, and full scale IQ scales.

Pragmatic Judgment The Pragmatic Judgment measure from the Comprehensive Assessment of Spoken Language (CASL: Carrow-Woolfolk 1999) was also included. The Pragmatic Judgment subtest measures the child's knowledge and use of appropriate language within a social context. It was designed to be used for individuals as young as 3 years of age and was normed on a nationwide standardization sample of 1 , 700 individuals. Internal reliabilities for the CASL subtests range from 0.64 to 0.94 , with most being in the $0.80 \mathrm{~s}$ and $0.90 \mathrm{~s}$. The examiner reads a situation that represents some aspect of everyday life that requires communication or a pragmatic judgment on the part of the child. The child must respond with the appropriate thing to say or do in the situation. 
This measure was included given the important role of social language, or language within a social context, for the development of EF in children.

Inhibition: Statue Statue (STA) is a measure from the NEPSY (Korkman et al. 1998) and measures motor persistence and inhibition. The child is asked to maintain a body position with eyes closed during a 75-s period and to inhibit the impulse to respond (i.e., body movement, vocalization, opening eyes) to distractors. Higher scores indicate better inhibition ability. Statue which is a standardized and normreferenced instrument designed to assess neuropsychological development in preschool- and school-aged children. Normative data for this test comes from the NEPSY standardization sample which was comprised of 1,000 children ranging in age from 3 to 12 years, stratified to match 1995 US Census data based on age, gender, race/ethnicity, geographic region, and parent education, and had moderate to high internal consistency values.

Attention: Visual Attention (VAT) The Visual Attention measure was selected from the NEPSY (Korkman et al. 1998) as a standardized and norm-referenced measure of basic attention. Visual Attention measures the speed and accuracy with which a child is able to focus selectively on and maintain attention to visual targets within an array. The child is asked to scan an array of pictures and mark the targets as quickly and accurately as possible. Normative data for this test comes from the NEPSY standardization sample which was comprised of 1,000 children ranging in age from 3 to 12 years, stratified to match 1995 US Census data based on age, gender, race/ethnicity, geographic region, and parent education, and had moderate to high internal consistency values.

\section{Procedure}

Children were tested individually at a daycare center in a quiet room by a trained graduate student examiner. Each assessment session occurred in the morning, lasting between 30 and $45 \mathrm{~min}$. Both the language and EF batteries used a fixed task order designed to maintain the child's maximal interest over the course of the assessment session.

\section{Analysis}

A maximum likelihood procedure (SPSS v. 21) with direct oblimin rotation was used for factor extraction. Factor selection criteria included eigenvalues greater than 1.0 (Gorsuch 1983) was also used along with qualitative interpretations of factor loadings for determining the interpretability of different factor solutions (Stevens 1996). Since direct oblimin EFA is used, both pattern and structure matrices will be reported. If EFA analysis identifies a factor solution with more than 1 eigenvalue, chi-square values of model fit will be obtained for factor models with less eigenvalues. For example if EFA extracts five factors with eigenvalues of 1.0 or greater, then chi-square fit indices will be obtained for factor models with one to four factors. Chi-square difference testing will provide information on the degree of difference across differing factor models.

\section{Results}

Descriptive statistics including means and standard deviations are reported in Table 1. Correlations for all measures are reported in Table 2.

Results from the Bartlett's Test of Sphericity (Bartlett $1950)$ indicated non-random correlations $\left(X^{2}=160.34\right.$, $d f=36, p<0.000)$. The Kaiser-Meyer-Olkin measure of sampling adequacy was 0.85 ; thus, the sample size used for this study was within acceptable standards (Cerny and Kaiser 1977). Factors with eigenvalues greater than 1.0 were extracted (Gorsuch 1983; Stevens 1996), which resulted in a threefactor solution. Table 3 provides the percentage of variance explained for each factor. Table 4 provides factor correlations of the three-factor model. As indicated in the table, moderate factor correlations were found between factor 1 and 2 $(r=0.59)$, moderate correlation between factor 1 and factor 3 $(r=0.34)$, and a relatively low correlation between factor 2 and factor $3(r=0.19)$.

Table 5 provides factor loadings for the Pattern Matrix and Table 6 provides loadings for Structure Matrix. While both are informative, results are invariant across Tables 4 and 5, although interpretive emphasis is based on the Pattern Matrix since it provides the unique relationship of a variable with each factor. Measures with at least a factor loading of 0.40 which indicates at least a $16 \%$ sharing of variance between the measure and the factor were considered for interpretation (Stevens 1996), although all loadings are reported. As predicted, each of the three-core cognitive constructs included in the

Table 1 Descriptive statistics

\begin{tabular}{llrrr}
\hline Variable & Analysis $N^{\mathrm{a}}$ & Missing $n$ & \multicolumn{1}{l}{ M } & \multicolumn{2}{l}{$S D$} \\
\hline Cognitive & & & & \\
$\quad$ PPVT-III & 69 & 3 & 53.21 & 20.43 \\
Pragmatic judgment & 69 & 10 & 8.76 & 4.50 \\
$\quad$ Statue & 69 & 6 & 18.03 & 6.67 \\
$\quad$ Visual attention & 69 & 7 & 12.45 & \\
Executive functions & 69 & 0 & & \\
$\quad$ Verbal working memory & 69.80 & 3.24 \\
Nonverbal working memory & 69 & 0 & 9.33 & 3.68 \\
Dimensional change sorting task & 69 & 6 & 21.64 & 2.77 \\
Cat-dog & 69 & 6 & 10.75 & 4.32 \\
Tower & 69 & 6 & 3.76 & 2.80 \\
\hline
\end{tabular}

${ }^{a}$ For each variable, missing values were replaced with the variable mean 
Table 2 Correlation matrix

\begin{tabular}{|c|c|c|c|c|c|c|c|c|}
\hline Variable & 1 & 2 & 3 & 4 & 5 & 6 & 7 & 8 \\
\hline \multicolumn{9}{|l|}{1 PPVT-III } \\
\hline 2 Pragmatic judgment & $0.65 * *$ & & & & & & & \\
\hline 3 Verbal working memory & $0.69 * *$ & $0.50 * *$ & & & & & & \\
\hline 4 Nonverbal working memory & $0.52 * *$ & $0.39 * *$ & $0.51 * *$ & & & & & \\
\hline 5 Dimensional change sorting task & $0.26^{*}$ & 0.19 & $0.30^{*}$ & $0.30 *$ & & & & \\
\hline 6 Visual attention & $0.29 *$ & 0.19 & $0.27 *$ & $0.35 * *$ & 0.07 & & & \\
\hline 7 Statue & $0.29 *$ & 0.24 & $0.38 * *$ & $0.43 * *$ & $0.39 * *$ & 0.09 & & \\
\hline 8 Cat-dog & $0.42 * *$ & $0.40 * *$ & $0.37 * *$ & $0.39 * *$ & $0.33^{*}$ & 0.24 & $0.30 *$ & \\
\hline 9 Tower & $0.48 * *$ & $0.43 * *$ & $0.44 * *$ & $0.37 * *$ & $0.33 *$ & 0.02 & $0.29 *$ & 0.23 \\
\hline
\end{tabular}

$N=69$

Note. $* p<0.05 ; * * p<0.01$ level of significance

study were defining of each factor, as indicated by magnitude of factor loadings. Factor 1 was defined by language measures (PPVT-III, Pragmatic Judgment) and also included Verbal Working Memory and the Tower measure. Factor 2 was defined by a measure of inhibition (Statue) and included Dimensional Card Sort and Nonverbal WM. Finally, factor 3 was defined by attention but did not include any EF measures with loadings greater than 0.40. Although the Cat-Dog task, which is a measure of conceptual set-shifting, had moderate cross-loadings on all three factors, it was the only measure that did not have high loadings of at least 0.40 on any single factor. Similarly, nonverbal WM was cross-loaded on all three factors but did load more highly on factor 2 .

Since EFA suggested three factors with eigenvalues greater than 1.0 and a non-significant chi-square goodness-of-fit $X^{2}$ $(12, N=69)=4.24, p=0.98$, chi-square's were obtained for a 1 and 2 factor solution. Table 7 provides goodness-of-fit values for models $1-3$. Table 8 provides model-fit comparisons for each model using chi-square difference testing. No significant differences were found between the different comparisons of models $1-3$.

\section{Discussion}

Executive functions are an important, but difficult to define construct (Barkley 2012). The present study investigated the construct validity of EF measures in early childhood using a diverse collection of measures that include verbal WM, nonverbal WM, problem-solving, and set-shifting. Additionally, select cognitive measures of language, inhibition, and attention were included as developmental cognitive markers of EF due to their foundational emphasis in different models of EF. Results from this study suggest language and inhibition are two core developmental foundations for EF in preschool children. Additionally, results from the current study suggest attention, although important in theoretical models of EF, does not appear to be a significant contributor to EF development in preschool children.

Cognitive markers (language, inhibition, and attention) included in this study defined each factor, based on the magnitude of the loadings, as predicted. Broadly, the extracted factors from the data suggest language, inhibition and attention are separable dimensions but language and inhibition, not
Table 3 Total variance explained by factor

\begin{tabular}{|c|c|c|c|c|c|c|}
\hline \multirow[t]{2}{*}{ Factor } & \multicolumn{3}{|c|}{ Initial eigenvalues } & \multicolumn{3}{|c|}{ Extraction sums of squared loadings } \\
\hline & Total & $\%$ of variance & Cumulative $\%$ & Total & $\%$ of variance & Cumulative $\%$ \\
\hline 1 & 3.866 & 42.951 & 42.951 & 3.316 & 36.849 & 36.849 \\
\hline 2 & 1.115 & 12.393 & 55.344 & .624 & 6.928 & 43.777 \\
\hline 3 & 1.000 & 11.116 & 66.460 & .580 & 6.443 & 50.220 \\
\hline 4 & 0.729 & 8.101 & 74.561 & & & \\
\hline 5 & 0.634 & 7.048 & 81.609 & & & \\
\hline 6 & 0.505 & 5.613 & 87.222 & & & \\
\hline 7 & 0.464 & 5.154 & 92.376 & & & \\
\hline 8 & 0.426 & 4.732 & 97.109 & & & \\
\hline 9 & 0.260 & 2.891 & 100.000 & & & \\
\hline
\end{tabular}


Table 4 Factor correlation matrix

\begin{tabular}{llll}
\hline Factor & 1 & 2 & 3 \\
\hline 1 & 1 & 0.588 & 0.340 \\
2 & 0.588 & 1 & 0.190 \\
3 & 0.340 & 0.190 & 1 \\
\hline
\end{tabular}

attention, are core cognitive components of $\mathrm{EF}$ measures in early childhood. Additionally, based on factor correlation and factor model comparisons, there is likely a large degree of overlap between language and inhibition abilities in preschool children. Consequently, the current study provides some support to a multidimensional view of EF that includes an underlying dimension characterized by the use of language in problem-solving and a second dimension characterized by inhibition and motor control in problem-solving that is less reliant on language processes.

Theoretically, the dimensional structure of EF in early childhood remains unresolved (Barkley 1997a, b, 2001; Rosenberg 2014). Results from the current study are theoretically informative in that a multi-dimensional model of EF in early childhood with developmental foundations of language and inhibition is supported. The importance of language, inhibition, and attention as foundational skills for EF has independently been important for different models of EF. However, it may be the case that each of these abilities are important but for different EF components. For example, working memory has been found in several previous studies to be an important component of EF (Monette et al. 2011; Nee et al. 2013). Working memory was also found to be important in this study; however, the current study adds to the literature in suggesting the degree of language demands in WM tasks is an important distinguishing quality of EF tasks in preschool children. Theoretically, the verbal WM tasks involve the 'phonological loop' as described by Baddeley and Hitch (1994).

Table 5 Pattern matrix using maximum likelihood extraction and Oblimin with Kaiser normalization rotation method

\begin{tabular}{lrrr}
\hline & \multicolumn{2}{l}{ Factor } & \\
\cline { 2 - 4 } & \multicolumn{1}{c}{2} & \multicolumn{1}{c}{3} \\
\hline PPVT-III & 0.962 & -0.127 & 0.082 \\
Pragmatic judgment & 0.732 & -0.052 & 0.004 \\
Verbal working memory & 0.618 & 0.163 & 0.118 \\
Tower & 0.503 & 0.235 & -0.201 \\
Statue & -0.033 & 0.684 & 0.028 \\
Dimensional change sorting task & -0.002 & 0.598 & -0.043 \\
Nonverbal working memory & 0.244 & 0.399 & 0.304 \\
Cat-dog & 0.235 & 0.288 & 0.191 \\
Visual attention & 0.005 & 0.002 & 0.737 \\
\hline
\end{tabular}

Rotation converged in five iterations
Table 6 Structure matrix using maximum likelihood extraction and Oblimin with Kaiser normalization rotation method

\begin{tabular}{llll}
\hline & \multicolumn{2}{l}{ Factor } & \\
\cline { 2 - 4 } & 1 & 2 & 3 \\
\hline PPVT-III & 0.915 & 0.455 & 0.385 \\
Verbal working memory & 0.753 & 0.548 & 0.358 \\
Pragmatic judgment & 0.703 & 0.380 & 0.243 \\
Tower & 0.573 & 0.493 & 0.014 \\
Cat-dog & 0.469 & 0.463 & 0.326 \\
Statue & 0.379 & 0.670 & 0.147 \\
Nonverbal working memory & 0.582 & 0.600 & 0.463 \\
Dimensional change sorting task & 0.335 & 0.589 & 0.070 \\
Visual attention & 0.256 & 0.145 & 0.739 \\
\hline
\end{tabular}

Baddeley et al. (1998) have demonstrated that across early and middle childhood, vocabulary knowledge is strongly associated with "phonological loop" capacity. That is, children who perform well on verbal working memory tasks also have good vocabulary knowledge. As suggested by Barkley (1997a, b), children's use of self-directed speech in service of selfregulation is partially dependent on the capacity to retain verbal rules in working memory. This theoretical explanation may explain why other measures like the Tower measure, which involves complex problem-solving with no explicit language requirements, also loaded on the same factor as language and verbal working memory measures. Future research may clarify the developmental emergence of these different abilities to determine the degree in which they are causally associated.

Inhibition was also found to define an EF dimension as evidenced by high loadings on the second factor, which also included measures of non-verbal working memory and setshifting. Because the day-night task requires the inhibition of a pre-potent response, it is understandable why the daynight measure loaded on a factor with inhibition measures. However, why inhibition was not related to performance on the measure is unclear. Arguably the Tower measure also requires children to inhibit reflexive responses in order to plan for motor actions. Perhaps inhibition is a necessary but insufficient component of complex problem solving that likely also requires abstract thinking sub served by verbal WM.

Interestingly, Nonverbal WM was found to be cross-loaded on all 3 extracted dimensions but not prominent on any one dimension. It is possible nonverbal WM may have a more
Table 7 Goodness-of-fit test matrix

\begin{tabular}{lrll}
\hline Model & \multicolumn{1}{l}{$X^{2}$} & $d f$ & $p$ \\
\hline 1 & 23.003 & 27 & 0.685 \\
2 & 10.463 & 19 & 0.941 \\
3 & 4.241 & 12 & 0.979 \\
\hline
\end{tabular}


Table 8 Comparative fit of factor analysis models

\begin{tabular}{lcrl}
\hline Model comparison & $\Delta X^{2}$ & $\Delta d f$ & $p$ \\
\hline 1 vs 2 & 12.54 & 8 & 0.1286875 \\
1 vs 3 & 18.762 & 15 & 0.22472219 \\
2 vs 3 & 6.222 & 7 & 0.51408009 \\
\hline
\end{tabular}

general influence across all measures of EF in early childhood that could be better explored as a higher-order latent variable model. Growth in children's 'visuospatial sketchpad' capacity, as described by Baddeley and Hitch (1994), has been found to be largely dependent on maturation of visual processing centers in the right hemisphere (Barkley 1997a, b). Likewise, the use of visuo-spatial stimuli, which are less amenable to verbal encoding than conceptual stimuli (Pickering et al. 2001), may help to explain these results.

Of additional interest in the current study is the use of a model fitting approach to examine trade-offs of using different models. Using chi-square as the primary indicator of model fit, there was evidence that a one-, two-, and three-factor model all provided a relatively good fit to the data. Additionally, in comparing different models, there was not a significant difference in fit across the different models. Consequently, by rule of parsimony, a one-factor model may be determined to be the best fit. However, a two-factor model was retained in the current study primarily because of the a priori selection criteria (eigenvalues $>1.0$ ) and the theoretical basis of the derived factors.

There were several limitations in the present study that may have limited findings and can inform future research. Although adequate, the sample size used in this study may have limited statistical power to detect effects of factor solutions with more than three dimensions. Additionally, the current study only used three developmental cognitive markers, which may have influenced the extracted factors. Although these three measures were included for theoretical reasons, future studies may consider adding additional measures that are of theoretical relevance. The task demands of the attention measure used in the study, which was primarily visualbased, may not have been an adequate representation of attention as used in EF measures. For instance, the NEPSY Visual Attention subtest is regarded as a measure of selective attention (Mahone and Schneider 2012). Additional measures of attention that provide a more comprehensive measurement of different components of attention should be investigated before attention can be definitively rule-out as having minimal impact on early childhood EF performance. These components include divided attention, sustained attention, and auditory measures that encompass these components as well as selective attention. Future research may benefit by investigating larger batteries of $\mathrm{EF}$ measures with more diverse task demands, especially with measures of attention. Finally, the parental education level of participants in the study was higher than average. The degree to which the results of the current study generalize to children of parents with lower education levels is unknown and should be investigated in future studies.

Despite these limitations, the present study provided insights into the measurable EF dimensions in early childhood. For example, WM was found to be fractionated into Verbal and Nonverbal components, rather than unified. Verbal WM was most related to language and EF measures of problemsolving. Although the relationship between verbal WM and language is not surprising, the relationship with problemsolving is somewhat novel since the Tower measures is, on the whole, nonverbal.

While language ability (e.g., receptive vocabulary) has been found to statistically mediate the relationship between socioeconomic status and executive function in a sample of urban African-American kindergarteners (Noble et al. 2005), longitudinal studies examining the relationship between language, socioeconomic status, and executive function have not been carried out. Likewise, recent studies examining the relationship between socioeconomic status (e.g., parental education, occupation, and income) and executive function performance in young children have shown that lower-income children have disproportionately poor executive skills (Noble et al. 2005, 2007).

Finally, although not addressed specifically in this study, the growth of EF skills may also reveal important relationships in EF factors. This finding suggests that future research should investigate factors that influence not just growth in executive skills, but also initial status in these abilities at the beginning of the preschool period. Such investigations may help inform the numerous attempts to experimentally intervene to improve the growth of EF in early childhood. While numerous interventions have been used to improve higherlevel thinking skills in children, results from the present study suggest interventions in EF may consider verbal WM and behavioral inhibition as important components to such interventions.

\section{Compliance with Ethical Standards}

Conflict of Interest The authors declare that they have no conflict of interest.

Ethical Approval All procedures performed in studies involving human participants were in accordance with the ethical standards of the institutional and/or national research committee and with the 1964 Helsinki declaration and its later amendments or comparable ethical standards. This article does not contain any studies with animals performed by any of the authors.

Informed Consent Informed consent was obtained from all individual participants included in the study. 


\section{References}

Anderson, V., Anderson, P. J., Jacobs, R., \& Smith, M. S. (2008). Development and assessment of executive function: from preschool to adolescence. In V. Anderson, R. Jacobs, \& P. J. Anderson (Eds.), Executive functions and the frontal lobes: a lifespan perspective (pp. 123-154). New York: Taylor \& Francis.

Baddeley, A. D. (1986). Working memory. Oxford: Psychology Press.

Baddeley, A. D., \& Hitch, G. J. (1994). Developments in the concept of working memory. Neuropsychology, 8, 485-493.

Baddeley, A. D., Gathercole, S., \& Papagno, C. (1998). The phonological loop as a language learning device. Psychological Review, 105, 158-173.

Barkley, R. A. (1997a). ADHD and the nature of self-control. New York: Guilford.

Barkley, R. A. (1997b). Behavioral inhibition, sustained attention, and executive functions: constructing a unifying theory of adhd. Psychological Bulletin, 121(1), 65-94.

Barkley, R. A. (2001). The executive functions and self-regulation: an evolutionary neuropsychological perspective. Neuropsychology Review, 11, 1-29.

Barkley, R. A. (2012). Executive functions: what they are, how they work, and why they evolved. New York: Guilford Publications.

Bartlett, M. S. (1950). Tests of significance in factor analysis. British Journal of statistical psychology, 3(2), 77-85.

Beauchamp, M., Catroppa, C., Godfrey, C., Morse, S., Rosenfeld, J. V., \& Anderson, V. (2011). Selective changes in executive functioning ten years after severe childhood traumatic brain injury. Developmental Neuropsychology, 36(5), 578-595. doi:10.1080/87565641.2011. 555572.

Blain-Briere, B., Bouchard, C., \& Bigras, N. (2014). The role of executive functions in the pragmatic skills of children age 4-5. Frontiers in Psychology, 5, 240. doi:10.3389/fpsyg.2014.00240.

Blair, C. (2002). Integrating cognition and emotion in a neurobiological conceptualization of children's functioning at school entry. American Psychologist, 57, 111-127.

Bodrova, E., \& Leong, D. J. (2006). Self-regulation as key to school readiness: how early childhood teachers promote this critical competency. In M. Zaslow \& I. Martinez-Beck (Eds.), Critical issues in early childhood professional development (pp. 203-224). Baltimore: Paul H. Brookes Publishing.

Breckenridge, K., Braddick, O., \& Atkinson, J. (2013). The organization of attention in typical development: a new preschool attention test battery. British Journal of Developmental Psychology, 31(Pt 3), 271-288. doi:10.1111/bjdp.12004.

Bull, R., \& Scerif, G. (2001). Executive functioning as a predictor of children's mathematics ability: inhibition, switching, and working memory. Developmental Neuropsychology, 19, 273-293.

Carlson, S. M. (2005). Developmentally sensitive measures of executive function in preschool children. Developmental Neuropsychology, $28,595-616$.

Cerny, B. A., \& Kaiser, H. F. (1977). A study of a measure of sampling adequacy for factor-analytic correlation matrices. Multivariate Behavioral Research, 12(1), 43-47.

Carrow-Woolfolk, E. (1999). Comprehensive Assessment of Spoken Language (CASL). Circle Pines, MN: AGS

Corkum, V., Byrne, J. M., \& Ellsworth, C. (1995). Clinical assessment of sustained attention in preschoolers. Child Neuropsychology, 1(1), 3-18.

Decker, S. L., Hill, S. K., \& Dean, R. S. (2007). Evidence of construct similarity in executive functions and fluid reasoning abilities. International Journal of Neuroscience, 117(6), 735-748.

Diamond, A. (2001). A model system for studying the role of dopamine in prefrontal cortex during early development in humans. In C.
Nelson \& M. Luciana (Eds.), Handbook of developmental cognitive neuroscience (pp. 433-472). Cambridge, MA: MIT Press.

Diamond, A. (2002). Normal development of prefrontal cortex from birth to young adulthood: cognitive functions, anatomy, and biochemistry. In D. Stuss \& R. Knight (Eds.), Principles of frontal lobe function (pp. 466-503). New York: Oxford University Press.

Duncan, G. J., Dowsett, C. J., Claessens, A., Magnuson, K., Huston, A. C., Klevanov, P., et al. (2007). School readiness and later achievement. Developmental Psychology, 43, 1428-1446.

Dunn, L. M., \& Dunn, L. M. (1997). Peabody Picture Vocabulary Test (3rd ed.). Circle Pines, MN: AGS.

Eisenberg, N., Fabes, R. A., \& Losoya, S. (1997). Emotional responding: regulation, social correlates, and socialization. In P. Salovey \& D. Sluyter (Eds.), Emotional development and emotional intelligence: educational implications. New York: Basic Books.

Espy, K. A. (1997). The Shape School: assessing executive function in preschool children. Developmental Neuropsychology, 13, 495-499.

Espy, K., Kaufmann, P., McDiarmid, M., \& Glisky, M. (1999). Executive functioning in preschool children: performance on A-not-B and other delayed response format tasks. Brain and Cognition, 41, 178-199.

Frye, D., Zelazo, P. D., \& Palfai, T. (1995). Theory of mind and rulebased reasoning. Cognitive Development, 10, 483-527.

Garon, N., Bryson, S. E., \& Smith, I. M. (2008). Executive function in preschoolers: a review using an integrative framework. Psychological Bulletin, 134(1), 31-60. doi:10.1037/0033-2909. 134.1.31.

Gerstadt, C. L., Hong, Y. J., \& Diamond, A. (1994). The relationship between cognition and action: performance of children $31 / 2-7$ years old on a stroop-like day-night test. Cognition, 53, 129-153.

Golden, C. (1981). The Luria-Nebraska children's battery: theory and formulation. In G. W. Hynd \& J. E. Obrzut (Eds.), Neuropsychological assessment of the school-aged child (pp. 277302). New York: Grune \& Stratton.

Gorsuch, R. L. (1983). Factor analysis (2nd ed.). Hillsdale, NJ: Erlbaum.

Halstead, W. C. (1947). Brain and intelligence: a quantitative study of the frontal lobes. Chicago: University of Chicago Press.

Kirkham, N. Z., Cruess, L., \& Diamond, A. (2003). Helping children apply their knowledge to their behavior on a dimension-switching task. Developmental Science, 6, 449-476.

Klenberg, L., Korkman, M., \& Lahti-Nuuttila, P. (2001). Differential development of attention and executive functions in 3- to 12-yearold Finnish children. Developmental Neuropsychology, 20(1), 407428. doi:10.1207/S15326942DN20016.

Kochanska, G., Murray, K. T., Jacques, T. Y., Koenig, A. L., \& Vandegeest, K. A. (1996). Inhibitory control in young children and its role in emerging internalization. Child Development, 67, 490-507.

Korkman, M., Kirk, U., \& Kemp, S. (1998). NEPSY: a developmental neuropsychological assessment. Chicago: Psychological Corporation.

Lehto, J. E., Juujärvi, P., Kooistra, L., \& Pulkkinen, L. (2003). Dimensions of executive functioning: evidence from children. British Journal of Developmental Psychology, 21, 59-80.

Lerner, M. D., \& Lonigan, C. J. (2014). Executive function among preschool children: unitary versus distinct abilities. Journal of Psychopathology and Behavioral Assessment, 36(4), 626-639. doi:10.1007/s10862-014-9424-3.

Levin, H. S., Culhane, K. A., Hartmann, J., Evankovich, K., Mattson, A. J., Harward, H., et al. (1991). Developmental changes in performance on tests of purported frontal lobe functioning. Developmental Neuropsychology, 7, 377-395.

Lezak, M. D. (1995). Neuropsychological assessment (3rd ed.). New York: Oxford University Press.

Luria, A. R. (1961). In J. Tizard (Ed.), The role of speech in the regulation of normal and abnormal behavior. New York: Liveright. 
Luria, A. R. (1973). The working brain. New York: Basic Books.

Luria, A. R. (1980). Higher cortical functions in man (2nd ed.). New York: Basic Books.

Mahone, E. M., \& Schneider, H. E. (2012). Assessment of attention in preschoolers. Neuropsychology Review, 22(4), 361-383.

Mahone, E. M., Pillion, J. P., \& Hiemenz, J. R. (2001). Initial development of an auditory continuous performance test for preschoolers. Journal of Attention Disorders, 5(2), 93-106.

McClelland, M. M., Cameron, C. E., Connor, C. M., Farris, C. L., Jewkes, A. M., \& Morrison, F. J. (2007). Links between behavioral regulation and preschoolers' literacy, vocabulary, and math skills. Developmental Psychology, 43, 947-959.

Miller, K. J. (2005). Executive functions. Pediatric Annals, 34(4), 310-317.

Miller, M. R., Giesbrecht, G. F., Muller, U., McInerney, R. J., \& Kerns, K. A. (2012). A latent approach to determining the structure of executive function in preschool children. Journal of Cognition and Development, 13(3), 395-423.

Miyake, A., Friedman, N. P., Emerson, M. J., Witzki, A. H., \& Howerter, A. (2000). The unity and diversity of executive functions and their contributions to complex "frontal lobe" tasks: a latent variable analysis. Cognitive Psychology, 41, 49-100.

Monette, S., Bigras, M., \& Guay, M. C. (2011). The role of the executive functions in school achievement at the end of grade 1. Journal of Experimental Child Psychology, 109(2), 158-173. doi:10.1016/j. jecp.2011.01.008.

Monette, S., Bigras, M., \& Lafrenière, M. A. (2015). Structure of executive functions in typically developing kindergarteners. Journal of Experimental Child Psychology, 140, 120-139. doi:10.1016/j.jecp. 2015.07.005.

Müller, U., Jacques, S., Brocki, K., \& Zelazo, P. D. (2009). The executive functions of language in preschool children. In A. Winsler, C. Fernyhough, \& I. Montero (Eds.), Private speech, executive functioning, and the development of verbal self-regulation (pp. 53-68). New York: Cambridge University Press.

Nee, D. E., Brown, J. W., Askren, M. K., Berman, M. G., Demiralp, E., Krawitz, A., \& Jonides, J. (2013). A meta-analysis of executive components of working memory. Cerebral Cortex, 23(2), 264282. doi:10.1093/cercor/bhs007.

Noble, K. G., Norman, M. F., \& Farah, M. J. (2005). Neurocognitive correlates of socioeconomic status in kindergarten children. Developmental Science, 8, 74-87.

Noble, K. G., McCandliss, B. D., \& Farah, M. J. (2007). Socioeconomic gradients predict individual differences in neurocognitive abilities. Developmental Science, 10, 464-480.

Pennington, B. F. (2009). Diagnosing learning disorders: a neuropsychological framework. New York: The Guilford Press.

Pennington, B. F., \& Ozonoff, S. (1996). Executive functions and developmental psychopathology. Journal of Child Psychology and Psychiatry, 37, 51-87.

Perner, J., \& Lang, B. (1999). Development of theory of mind and executive control. Trends in Cognitive Sciences, 3, 337-344.

Pickering, S. J., Gathercole, S. E., Hall, M., \& Lloyd, S. A. (2001). Development for memory of pattern and path: further evidence for the fractionation of visuo-spatial memory. Quarterly Journal of Experimental Psychology, 54, 397-420.
Posner, M. I., Rothbart, M. K., Sheese, B. E., \& Voelker, P. (2012). Control networks and neuromodulators of early development. Developmental Psychology, 48(3), 827-835. doi:10.1037/ a0025530.

Roid, G. H. (2003). Stanford-Binet Intelligence Scales (5th ed.). Itasca, IL: Riverside.

Rosenberg, L. (2014). The associations between executive functions' capacities, performance process skills, and dimensions of participation in activities of daily life among children of elementary school age. Applied Neuropsychology Child. doi:10.1080/21622965.2013. 821652. 1-9.

Smidts, D. P., Jacobs, R., \& Anderson, V. (2004). The object classification task for children (OCTC): a measure of concept generation and mental flexibility in early childhood. Developmental Neuropsychology, 26, 385-401.

Sowell, E. R., Trauner, D. A., Gamst, A., \& Jernigan, T. L. (2002). Development of cortical and subcortical brain structures in childhood and adolescence: a structural MRI study. Developmental Medicine and Child Neurology, 44(1), 4-16.

Stevens, J. (1996). Applied multivariate statistics for the social sciences (3rd ed.). Mahwah, NJ: Lawrence Erlbaum Associates.

Stuss, D. T., \& Alexander, M. P. (2000). Executive functions and the frontal lobes: a conceptual view. Psychological Research, 63, 289-298.

Van der Ven, S. H., Kroesbergen, E. H., Boom, J., \& Leseman, P. P. (2012). The development of executive functions and early mathematics: a dynamic relationship. British Journal of Educational Psychology, 82(1), 100-119. doi:10.1111/j.2044-8279.2011. 02035.x.

Van der Ven, S. H., Kroesbergen, E. H., Boom, J., \& Leseman, P. P. (2013). The structure of executive functions in children: a closer examination of inhibition, shifting, and updating. British Journal of Developmental Psychology, 31(Pt 1), 70-87. doi:10.1111/j. 2044-835X.2012.02079.x.

Vugs, B., Hendriks, M., Cuperus, J., \& Verhoeven, L. (2014). Working memory performance and executive function behaviors in young children with SLI. Research in Developmental Disabilities, 35(1), 62-74. doi:10.1016/j.ridd.2013.10.022.

Vygotsky, L. S. (1978). Mind in society: The development of higher psychological processes (M. Cole, V. John-Steiner, S. Scribner, \& E. Souberman (Eds. \& Trans.). Cambridge, MA: Harvard University Press. (Original work published 1930, 1933, 1935).

Vygotsky, L. S. (1986). Thought and language. A. Kozulin (Ed. \& Trans.). Cambridge, MA: MIT Press. (Original work published 1934).

Welsh, M. C., Pennington, B. F., \& Groisser, D. B. (1991). A normativedevelopmental study of executive function: a window on prefrontal function in children. Developmental Neuropsychology, 7, 131-149.

Wiebe, S. A., Espy, K. A., \& Charak, D. (2008). Using confirmatory factor analysis to understand executive control in preschool children: I. Latent structure. Developmental Psychology, 44(2), 575-587.

Wiebe, S. A., Sheffield, T., Nelson, J. N., Clark, C. A., Chevali, N., \& Espy, K. A. (2011). The structure of executive function in 3-yearolds. Journal of Experimental Child Psychology, 108, 436-452.

Zelazo, P. D. (2004). The development of conscious control in childhood. Trends in Cognitive Sciences, 8, 12-17. 